\title{
Market Mavens: Psychological Influences
}

\author{
Ronald A. Clark \\ Florida State University \\ Ronald E. Goldsmith \\ Florida State University
}

\begin{abstract}
Market mavens are consumers who are highly involved in the marketplace and represent an important source of marketplace information to other consumers. Because of their influence on other consumers across a wide range of product domains, market mavens are particularly interesting to retailers. Previous studies have clarified the behavioral tendencies of market mavens. The present study focuses on psychological influences on market mavenism. A structural-equation model of the normative influences on the psychology of the market maven is developed and tested. The hypothesized model describes relationships between global psychological constructs (self-esteem, tendency to conform), consumer traits (susceptibility to interpersonal influence, consumer need for uniqueness), and a domain-specific tendency (opinion leadership), placing the market maven construct in a normative, nomological network. The hypothesized model was supported by the data. The findings reveal the complexity of the market maven by disclosing their susceptibility to normative influence despite their need for uniqueness. @ 2005 Wiley Periodicals, Inc.
\end{abstract}

Each year, businesses spend billions of dollars to market their products and services to consumers. In the United States, over 128 billion dollars was spent in 2003 on advertising alone (Vranica, 2004). With increasing competition in the marketplace and the increasing cost of promotion, a 
well-designed, targeted marketing approach is necessary for the survival of the business. As objects of these targeted communications, some consumers are more valuable than others because they influence others through interpersonal communication (Feick \& Price, 1987; Williams \& Slama, 1995). The marketing literature has identified three distinct types of influential consumers: the innovator, the opinion leader, and the market maven (Feick \& Price, 1987). All three types of influential consumers represent an attractive target to marketers because of their tendency to aid the spread of information in the marketplace. Innovators are defined as consumers who tend to adopt products comparatively early within a given social system (Rogers, 1995). A central concept to the diffusion of new products, the trait of innovativeness is present in all consumers to varying degrees (Midgley \& Dowling, 1978). Innovativeness has been discussed extensively in the marketing literature (cf. Im, Bayus, \& Mason, 2003; Rogers, 1995; Steenkamp, Hofstede, \& Wedel, 1999). Likewise, opinion leaders have received considerable attention in marketing research (e.g., Flynn, Goldsmith, \& Eastman, 1996; Leonard-Barton, 1985; Venkatraman, 1989). Opinion leaders are defined as individuals who influence the purchasing behavior of other consumers in a specific product domain (Flynn et al., 1996). By comparison, the concept of the market maven is relatively recent. Market mavens are defined as "individuals who have information about many kinds of products, places to shop, and other facets of markets, and initiate discussions with consumers and respond to requests from consumers for market information" (Feick \& Price, 1987, p. 85). Compared to innovativeness and opinion leadership, the literature on the market maven is less developed.

Both innovators and opinion leaders tend to be influential within specific product categories; therefore, innovativeness and opinion leadership are appropriately measured with domain-specific instruments (Flynn et al., 1996; Goldsmith \& Hofacker, 1991). By contrast, the market maven is a source of information about the marketplace in general (Feick \& Price, 1987). This marketplace orientation, rather than a product-specific orientation, makes market mavens particularly attractive targets to the superstore-type retailers that tend to dominate today's retail landscape. In other words, market mavens are likely to spread word-of-mouth communications across a variety of products, which makes them more attractive to retailers that sell a wide range of products. In contrast, innovators and opinion leaders tend to be experts within a specific product domain, which may make them less appealing targets to superstoretype retailers.

Much of the academic research on the market maven to date has focused on the demographics and behavioral dimensions of the market maven (Higie, Feick, \& Price, 1987; Laroche, Pons, Zgolli, Cervellon, \& Kim, 2003; Price, Feick, \& Guskey, 1995; Williams \& Slama, 1995). Little is known about the motivations or psychological attributes of the market maven. An important function of marketing research is to strive 
to understand the individual difference characteristics of our consumer taxonomies (Bettman, 1979). Accordingly, the purpose of the current study was to provide a better understanding of the psychology of market mavens in order to enhance the theoretical understanding of this influential consumer type and to provide managers some insight into effective ways to adjust their promotion strategies to appeal to market mavens. A review of relevant literature was conducted to ascertain individual differences that are nomologically related to mavenism. Based on existing theory, a model of the relationships between select individual differences and the market maven was hypothesized and tested. Results of the model evaluation are presented, along with managerial implications and suggestions for future research.

\section{THE RESEARCH MODEL}

Market mavens, by definition, are highly social consumers who engage in many discussions regarding the marketplace (Feick \& Price, 1987). With this in mind, the study focuses on individual-difference variables that describe the social psychology of the consumer. Market mavens are influential within groups of consumers; thus, it is likely that they contribute to the establishment of consumption norms. However, little is known about normative influences on the market maven. The model proposed in this study was designed to address this apparent gap in the marketing literature.

In accordance with the recommendations of Goldsmith, Freiden, and Eastman (1995) for constructing psychological models of individual differences, the hypothesized model is a hierarchical model that flows from a higher level of abstraction to a domain-specific variable. Specifically, the model depicts the domain-general (global) traits of self-esteem and tendency to conform as exogenous variables leading to the less abstract, consumer-specific traits of consumer susceptibility to normative interpersonal influence, consumer need for uniqueness, and market mavenism (endogenous variables in the model). From this consumer trait level, the model proceeds to a final endogenous variable, domain-specific opinion leadership. The hypothesized model is presented in Figure 1.

For the sake of parsimony, the model was limited to psychological traits that underlie the social responses of market mavens to normative pressure. The model can be described as having three tiers: (a) global personality traits, (b) consumer traits, and (c) a domain-specific trait. Global personality traits selected for the model were self-esteem and conformity. Self-esteem was included in the model because of its centrality in explaining human psychology and its influence on how individuals interact with other individuals (Rosenberg, 1979; Rosenberg, Schooler, Schoenbach, \& Rosenberg, 1995). Tendency to conform was selected because of its central role in the social-psychology literature explaining individual 


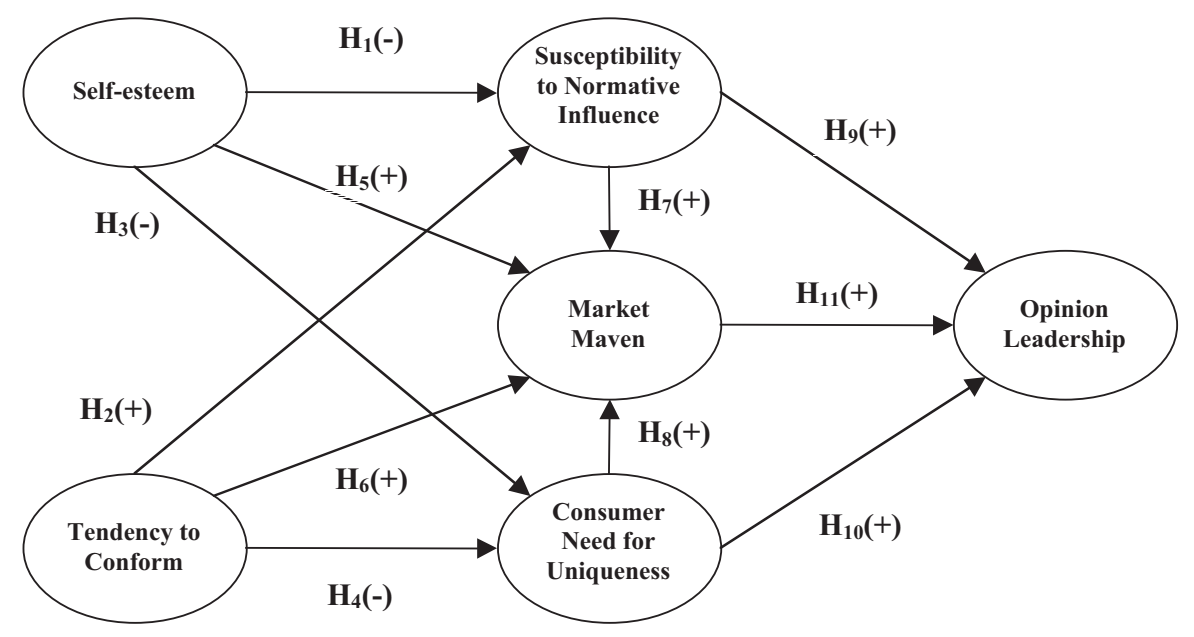

Figure 1. Hypothesized model.

responses to normative pressure and individual behavior in groups (Burn, 2004). Other global traits were considered for the model (e.g., self-monitoring), but were not identified in the literature as central to explaining normative responses of the individual to normative pressure. Consumer trait variables selected for the study were susceptibility to normative interpersonal influence, consumer need for uniqueness, and market mavenism (the focal construct). Social responses to normative pressure are generally manifested in either conforming or nonconforming behaviors. Therefore, it was important to select trait variables that captured consumer tendencies to conform and nonconform. The closest approximations of conformity and nonconformity in a consumer context are susceptibility to normative influence and consumer need for uniqueness, respectively. Finally, opinion leadership was selected as the domain-specific variable because of its close relationship to market mavenism and its ability to anchor the model in a nomological network. The theory basis for the relationships between the constructs follows.

\section{LITERATURE REVIEW AND HYPOTHESES}

\section{Self-Esteem}

Self-esteem is a key construct to understanding the underlying psychology behind much of human behavior as is evidenced by the thousands of academic studies that include self-esteem as a focal construct (Guindon, 2002; Rosenberg et al., 1995). Because of the vast literature on the topic, self-esteem has been ascribed several definitions. This study used the widely accepted view of self-esteem as a global personality construct that measures the extent to which a person has a positive attitude about him- or herself (Rosenberg, 1965, 1979). Guindon (2002, p. 207) 
refined the definition of global self-esteem as, "An overall estimate of general self-worth; a level of self-acceptance or respect for oneself; a trait or tendency relatively stable and enduring, composed of all subordinate traits and characteristics within the self." Consumer research on personality traits has utilized self-esteem to describe the position of consumer personality constructs within a nomological network (e.g., Eastman, Goldsmith, \& Flynn, 1999; Lascu \& Zinkhan, 1999).

\section{Tendency to Conform}

Reference groups can be an influential force in consumer behavior by establishing and enforcing social norms (Fisher \& Ackerman, 1998). Baron, Kerr, and Miller (1992) identify social norms as group-sanctioned perceptions, attitudes, and behaviors to which each member of the group is expected to adhere. Although norms are rarely formalized in writing or even discussed openly, the normative pressure that groups exert on individuals results in a high level of influence over a multitude of individual behaviors (Feldman, 1984). The importance of social norms is evident in the inclusion of norms as an important construct in consumer-behavior models, such as the Fishbein and Ajzen (1975) Theory of Reasoned Action. Early experimental studies by Asch (1953) and Sherif (1963) established conformity as a behavioral response of compliance with social norms. Willis (1965) presented a multidimensional view of social response to social influence that disclosed conformity as one element of a model that included both anticonformity and independence as nonconforming behaviors. Subsequently, Nail, MacDonald, and Levy (2000) refined and extended Willis's Diamond Model of Social Response in a series of subsequent studies on Social Response Theory (for a review, see Nail, MacDonald, \& Levy, 2000). Although conformity can be a situation-specific behavior, as was dramatically demonstrated by the Milgram (1963) experiments, personality plays a major role in the tendency to conform (Krech, Crutchfield, \& Ballachey, 1962). To understand the psychological attributes of the market maven, the focus of this study is directed on the personality component of conformity. For the purpose of this study, tendency to conform is defined as a global, enduring personality trait in which the individual is predisposed to acquiesce to social norms prescribed by reference groups that are relevant and important to the individual.

\section{Consumer Susceptibility to Normative Interpersonal Influence}

Bearden, Netemeyer, and Teel (1989, p. 474) defined consumer susceptibility to interpersonal influence as "the need to identify or enhance one's image with significant others through the acquisition and use of products and brands, the willingness to conform to the expectations of others regarding purchase decisions and/or the tendency to learn about products and services by observing others and/or seeking information from 
others." The theoretical development of susceptibility to interpersonal influence as a personality trait can be traced to the academic literature of the 1950s in psychology (e.g., Berkowitz \& Lundy, 1957; Deutsch \& Gerrard, 1955; Janis, 1954). McGuire (1968) reinforced the idea of susceptibility to interpersonal influence as a personality construct in his seminal work on influenceability. An early measure of susceptibility to interpersonal influence was developed by Park and Lessig (1977). The Park and Lessig (1977) scale was somewhat limited in that it was specific to both product and situation (Bearden et al., 1989). Further, as Bearden et al. (1989) observed, psychometric properties such as reliability, validity, and dimensionality were not reported. Bearden et al. (1989) subsequently developed and tested a two-factor consumer susceptibility to interpersonal influence (SUSCEP) scale that measures the construct as an enduring individual difference.

Deutsch and Gerrard (1955) described interpersonal influence as having two dimensions, informational and normative. Informational influence is indicated by a tendency to accept information from referent others as being indicative of reality (Deutsch \& Gerrard, 1955). Informational influence can result from actively seeking information from others or passively observing others (Park \& Lessig, 1977). The tendency to conform to the expectations of others is described as normative influence (Burnkrant \& Cousineau, 1975). Bearden et al. (1989) state that normative influence in a consumer context includes the need to utilize products and brands to enhance one's social image as well as the need to conform to the expectations of significant others. Normative influence has been subdivided conceptually into value-expressive influence and utilitarian influence (Bearden \& Etzel, 1982; Park \& Lessig, 1977). Although the division is valuable from a theoretical standpoint, empirical evidence for subdividing normative influence was not found (Bearden et al., 1989). Several consumer studies have treated normative and informational influence as separate constructs (e.g., Fisher \& Price, 1992; LaTour \& Manrai, 1989; Sen, Gurhan-Canli, \& Morwitz, 2001; Steenkamp \& Gielens, 2003). It is well known that market mavens represent an informational influence on others (Feick \& Price, 1987); however, the impact of normative influence on market mavens is unknown. In other words, market mavens influence others, but do others influence them? To answer this question the study focuses on the normative dimension of consumer susceptibility to interpersonal influence.

An early study by Janis (1954) indicated that individuals with low self-esteem are more easily influenced by others than are those higher in self-esteem. Individuals with low self-esteem will comply with the suggestions of others as an ego-defense mechanism to avoid social disapproval (Cox \& Bauer, 1964). McGuire (1968) posited that susceptibility to interpersonal influence is related to low self-esteem. An individual who is high in self-esteem would seem to be less likely to conform to normative pressure. Therefore, a consumer with high self-esteem would 
likely be less susceptible to normative interpersonal influence. This forms the foundation for the first hypothesis.

H1: Global self-esteem negatively affects consumer susceptibility to normative interpersonal influence.

Some researchers have treated conformity and social influence as synonymous constructs (Burnkrant \& Cousineau, 1975; Jahoda, 1959). Lascu and Zinkhan (1999) state that it is more accurate to view conformity and social influence as being conceptually distinct. Consumer research on interpersonal influence has emphasized conformity to social norms (Ford \& Ellis, 1980; Moschis, 1976; Stafford, 1966). Indeed, tendency to conform is a component of consumer susceptibility to normative interpersonal influence (Bearden et al., 1989). It can be expected that individuals who have a high tendency to conform would be more susceptible to the normative dimension of susceptibility to interpersonal influence. Hence, the second hypothesis is presented.

H2: Tendency to conform positively affects consumer susceptibility to normative interpersonal influence.

\section{Consumer Need for Uniqueness}

Although many consumers are very attentive to social cues from other consumers (Bearden \& Rose, 1990), it is important for consumer researchers to recognize that many consumers do not follow the majority (Bearden \& Etzel, 1982). In fact, some individuals actively strive to distinguish themselves from others by going against social norms (Snyder \& Fromkin, 1977). Certain consumers express their uniqueness through their product purchases (Simonson \& Nowlis, 2000). This tendency is described as consumer need for uniqueness, which is defined as an enduring personality trait by which consumers pursue dissimilarity through products and brands in an effort to develop a distinctive self and social image (Tian, Bearden, \& Hunter, 2001). Tian et al. (2001) described consumer need for uniqueness as having three dimensions: (a) creative choice counterconformity, (b) unpopular choice counterconformity, and (c) avoidance of similarity. Creative choice counterconformity is the tendency to select products and brands that are different from the established norms, but are still viewed as acceptable (Tian et al., 2001). Unpopular choice counterconformity is manifested as a tendency to make consumer choices that position the individual as distinct from the group (Tian et al., 2001). Avoidance of similarity is merely an intentional avoidance of commonly used products or brands (Tian et al., 2001). The counterconformity dimensions are of particular interest because they are analogous to anticonformity in a consumer 
context, which means they actively avoid compliance with established social norms.

In an individualistic culture such as the United States, it might be tempting to think of the consumer with high need for uniqueness as being high in self-esteem. By actively seeking to separate themselves from established social norms, it would appear that they have a level of self-confidence that allows them to stand out without embarrassment or remorse. Despite the intuitive appeal of this argument, the literature does not support this view. In fact, there is evidence that the motivation behind need for uniqueness actually stems from an unsatisfactory evaluation of self (Fromkin, 1972). This would indicate that individuals with a high need for uniqueness would be comparatively low in self-esteem. Some have posited that uniqueness lies on a continuum between total similarity and total dissimilarity; further, individuals who find themselves perceptually closer to the similarity end of the continuum experience dissatisfaction with themselves (Burns \& Warren, 1995). Conformity to social norms is often associated with rewards in the form of acceptance and social approval; however, negative evaluations can accompany behaviors that are perceived as "following the crowd" (Simonson \& Nowlis, 2000). Logically, if low self-esteem accompanies a high need for uniqueness, then high self-esteem would correspond to lower need for uniqueness. In a consumer context, consumers with high self-esteem would not feel the need to differentiate themselves from other consumers with their product and brand choices; whereas individuals low in self-esteem need to break social norms to have positive evaluations about themselves. This suggests a negative relationship between the two constructs. Hence, the third hypothesis is proposed.

H3: Global self-esteem negatively affects consumer need for uniqueness.

The definition of consumer need for uniqueness is the pursuit of dissimilarity from established social norms through product and brand purchases (Tian et al., 2001). The tendency to conform is obviously at odds with the need to be unique. Although there are conditions under which individuals high in need for uniqueness would tend to conform, the majority of these individuals will tend to go against group norms (Simonson $\&$ Nowlis, 2000). This is the premise of the fourth hypothesis.

H4: Tendency to conform negatively affects consumer need for uniqueness.

\section{Market Mavenism}

Feick and Price (1987) provided market researchers with the first description of the market maven as a consumer highly involved in the market- 
place. They described the market maven as a source of information about a multitude of products and brands as well as the marketplace in general (i.e., places to shop and sales). Market mavens are eager to share their marketplace knowledge with other consumers and are often sought by other consumers for information. It is no surprise then that consumers perceive market mavens as being influential in their purchase decisions. Subsequent research has provided a clearer picture of the behavior of the market maven. Market mavens are heavy users of coupons and may stimulate coupon use by others because they give away four times more coupons than nonmavens (Price, Feick, \& Guskey-Federouch, 1988). They provide more information about a wider range of services, durable goods, and nondurable goods (Slama \& Williams, 1990). Market mavens have larger evoked sets (Elliot \& Warfield, 1993). Moreover, they are more interested than nonmavens in smart buying (Slama, Nataraajan, \& Williams, 1992). They are more likely to engage in discussions about retail store image attributes and are heavier readers of direct-mail ads than nonmavens (Higie et al., 1987). Market mavens see price as an indicator of quality (Lichtenstein \& Burton, 1990). Market mavenism has also been found to be associated with everyday market helping behavior (Price et al., 1995). It especially makes sense for consumers to seek out market mavens in services, because market mavens have been shown to be more accurate in their assessment of service quality (Engelland, Hopkins, \& Larson, 2001). Market mavens tend to be more innovative, spend more time shopping, and spend more money than nonmavens (Goldsmith, Flynn, \& Goldsmith, 2003). Nataraajan and Angur (1997) identified the industrial maven as the counterpart to the consumer market maven, showing the strength of the construct.

Despite knowledge about some specific behaviors and tendencies of the maven, markedly less is known about the psychological attributes of the market maven. Feick and Price (1987) originally found mavens more likely to be minority, female, and less educated, in a sample of U.S. consumers. However, Wiedmann, Walsh, and Mitchell (2001) did not find these demographic differences to hold in a sample of German consumers. Knowledge of the psychological traits of the market maven is even more limited.

Individuals with high self-esteem have positive evaluations of their self-worth and a high level of respect for themselves (Rosenberg, 1965, 1979). Consumption is one way that consumers can increase their selfesteem (Zavestoski, 2002). Individuals with high self-esteem are less likely to feel isolated and more likely to engage in pro-social behavior (McWhirter, 1997; Van Dyne,Vanderwalle, Kostova, Latham, \& Cummings, 2000). It stands to reason that individuals with high levels of selfesteem would be more willing to engage in conversations about their product and brand choices. They would be less self-conscious about revealing their consumption habits to others and would be self-confident enough to function as an opinion leader of the general marketplace. This provides the theoretical foundation for the fifth hypothesis. 
H5: Global self-esteem positively affects market mavenism.

Tendency to conform is described as a general tendency toward complying with the expectations of referent others. The interactive nature of the market maven suggests that they operate within group norms. It is unlikely that an individual perceived as being deviant from the social norms prescribed by the group would be frequently sought out for opinions regarding consumption. Instead, it is probable that consumers would seek out consumers whose consumption habits are acceptable to the group. Indeed, consumers value the opinions of individuals whom they perceive as similar to themselves (Rogers, 1995). Consequently, it makes sense that individuals who tend to conform to social norms and are experts on the marketplace would be sought for their consumption opinions. This is the basis for the sixth hypothesis.

H6: Tendency to conform positively affects market mavenism.

Market mavens are highly involved with the marketplace and are highly interactive with other consumers (Feick \& Price, 1987). Much of the marketplace is driven by social norms. For example, department stores sell fashions that are in style according to the latest societal norms. In some ways, the marketplace is a reflection of the society it serves. As such, one would expect that normative influences that affect the marketplace would also affect the market maven. Market mavens are both sources of information and seekers of information (Higie et al., 1987). To effectively perform their role as a social communicator, market mavens cannot violate the norms of the social system in which they operate (Rogers, 1995). This would lead one to expect a positive relationship between normative susceptibility to interpersonal influence and market mavenism (Steenkamp \& Gielens, 2003). This line of reasoning forms the basis for the seventh hypothesis.

H7: Consumer susceptibility to normative interpersonal influence positively affects market mavenism.

A distinguishing characteristic of market mavens is that other consumers seek them out for marketplace information (Feick \& Price, 1987). The fact that market mavens are responsive to these requests implies that they are comfortable with this unique role. Indeed, the extent to which they engage in the exchange of information suggests that they recognize that they are dissimilar from other consumers and relish their function as a source of information. It is likely that market mavens know that other consumers are more aware of the market maven's product and brand consumption than the consumption of nonmavens because other consumers value the maven as an information source. Therefore, it is likely that mavens will feel the need to distinguish themselves from non- 
mavens through their purchases. The implication that need for uniqueness is high in an individual who is also high in susceptibility to normative influence is seemingly counterintuitive. However, the market maven's role in society as a social communicator of the marketplace dictates that they operate within social norms. If they do not operate within the prescribed norms of society, it is unlikely that consumers will seek them out for their consumption opinions. Perhaps market mavens are cognizant of the social norms related to consumption but put their own "spin" on their consumption habits to express their uniqueness within normative boundaries. This provides the basis for the eighth hypothesis.

H8: Consumer need for uniqueness positively affects market mavenism.

\section{Domain-Specific Opinion Leadership}

Opinion leadership is an important concept to marketing researchers and practitioners alike because of the influential role of the opinion leader in the marketplace and the contribution of the concept to models of consumer behavior (Rogers, 1995). Domain-specific opinion leadership is defined as consumer influence of individuals in specific product areas (Flynn et al., 1996). Opinion leaders represent a major source of word-ofmouth communication and can be either positive or negative in their communications (Gilly, Graham, Wolfinbarger, \& Yale, 1998; Leonard-Barton, 1985). Opinion leaders are selected on the basis of their product-specific expertise and their similarity to those who seek their opinion (Rogers, 1995). Fashion was chosen as the domain for opinion leadership in this study largely because the product domain performed well in the original scale development study and in previous studies of domain-specific opinion leadership (e.g., Flynn et al., 1996; Reynolds \& Darden, 1971).

By definition, opinion leaders communicate frequently with others regarding their product domain of expertise. As such, they are constrained by the norms of the social system in which they operate. They probably do not rely entirely on those norms to make decisions about the products of their expertise. However, to maintain their social role as a communicator of information, it is doubtful that they blatantly violate social norms. Accordingly, it would follow that opinion leaders are somewhat susceptible to normative interpersonal influence. This reasoning is the basis for forming the ninth hypothesis:

H9: Consumer susceptibility to normative interpersonal influence positively affects domain-specific opinion leadership in the domain of fashion.

Opinion leaders are deemed as experts in their specific product domain. In this way, they are unique from other consumers. The willing partici- 
pation of opinion leaders in their role would imply that this uniqueness is something that opinion leaders desire. Therefore, it makes sense that need for uniqueness provides a partial explanation for the opinion leader's desire to be seen as a leader in their specific product domain. In the specific product domain of fashion, uniqueness is achieved by being ahead of the adoption curve. This is the premise of the tenth hypothesis:

H10: Consumer need for uniqueness positively affects domain-specific opinion leadership in the domain of fashion.

Market mavenism and opinion leadership are closely related but conceptually distinct. Specifically, opinion leaders are influential in a specific category, whereas market mavens are influential across a large range of categories (Feick \& Price, 1987). Some researchers simply regard market mavens as generalized opinion leaders (Steenkamp \& Gielens, 2003). Indeed, Goldsmith et al. (2003) found empirical support for a positive correlation between market mavenism and generalized opinion leadership. Engelland et al. (2001) found a strong relationship between market mavenism and opinion leadership in services. One could expect a similar relationship to hold in the product domain of fashion. Accordingly, the following hypothesis is proposed.

H11: Market mavenism positively affects domain-specific opinion leadership in the domain of fashion.

\section{METHOD}

\section{Sample}

Data were collected with the use of 644 self-report questionnaires distributed at a large state university in the southeastern United States. The data collection was part of an undergraduate extra-credit exercise in marketing research. Students were asked to complete one survey themselves and then were trained to obtain a nonstudent quota sample following detailed restrictions. Specifically, each student was instructed to acquire two completed surveys from nonstudent consumers aged 25-34, two completed surveys from nonstudent consumers aged 35-45, and two surveys from individuals 45 and older. Other restrictions placed on the quota sample were (a) students were instructed to strive for an approximately equal distribution of gender, (b) respondents could not be students or employees of the university, and (c) each questionnaire had to have a valid phone number and first name for the respondent. Random verification of approximately $15 \%$ of the questionnaires was conducted by telephoning the respondents. No illegitimate questionnaires were detected in the verification process. 
Quality checks in the form of extra items were imbedded in the questionnaire to detect random response or otherwise bad respondents. The quality checks allowed for a Likert-type response format from 1 = strongly disagree to 7 = strongly agree. One item stated, "I have tried to answer all of these questions honestly and accurately." Respondents answering 5 or less were removed from the sample. A second item stated, "If you read this item, do not respond to it." Forty-six respondents were removed on the basis of "incorrect" answers to the quality checks, leaving a usable sample of 598 respondents.

The usable sample consisted of 598 consumers aged 18 to 83 years with a mean of $28.7(S D=12.4)$. The sample contained 287 males $(48 \%)$ and 310 females (52\%). One respondent did not indicate his or her sex. Respondents reported their ethnicity as 76\% (454) White or Caucasian, 13\% (74) African American, 7\% (40) Hispanic, and 4\% (4) "other." Four respondents declined to respond to the question.

\section{Measures}

The original questionnaire was tested in a pilot study with 32 students who were debriefed with regard to the questionnaire items. No hypothesis guessing was apparent in the interviews conducted immediately following the pilot study. Most of the scales utilized for the purpose of the study were adapted from existing literature. Personality measures tend to be comparatively lengthy in the number of items; therefore, subsets of scales were utilized to represent the constructs. Personality scales are robust to modification (item reduction) and perform in the same manner as the original scale as long as the reliability of the selected items is still acceptable (Villani \& Wind, 1975). Where possible, items that were indicated by previous research to perform better from a psychometric standpoint were included in the scale subsets. All scales used a 7-point Likerttype response format.

Global Self-Esteem. Global self-esteem was measured with the use of 8 items from Rosenberg's (1965) original 10-item self-esteem scale. The scale measures the extent to which a person has a positive attitude about him- or herself. A high score on the self-esteem scale represents a high level of self-esteem. A sample item is, "I take a positive attitude toward myself." Construct reliability via Fornell and Larcker (1981) was 0.89 for this construct. Individual parameter estimates ranged from 0.54 to 0.72 .

Tendency to Conform. Tendency to conform was measured with the use of a six-item bipolar adjective scale adapted from the Jackson (1976) Personality Inventory. The adjective pairs included in the scale were agreeing / disagreeing, acquiescent/resistant, adapting / inflexible, accommodating / opposing, cooperative / uncooperative, and concurring / differing 
and were scored on a 7-point, bipolar adjective format. The scale measures the global tendency of the individual to conform to social norms. Higher scores on the scale indicate a higher tendency to conform. Construct reliability was 0.85 for this construct. Individual parameter estimates ranged from 0.62 to 0.80 .

Consumer Susceptibility Normative Interpersonal Influence. Susceptibility to normative interpersonal influence was measured with the use of eight items from the normative factor of the Bearden et al. (1989) overall consumer susceptibility to interpersonal influence scale. The scale measures the extent to which consumers desire to enhance their social and self-image through product and brand purchases and are willing to conform to other consumers in their product and brand choices. Higher scores on the scale indicate the individual is more susceptible to normative influence. A sample item is, "If other people can see me using a product, I often purchase the brand they expect me to buy." Construct reliability was 0.93 for this construct. Individual parameter estimates ranged from 0.63 to 0.88 .

Consumer Need for Uniqueness. Consumer need for uniqueness was measured with 7 items from the counterconformity dimensions of the Tian et al. (2001) 31-item scale. The scale measures the extent to which an individual tends to use product and brand purchases to distinguish themselves from social norms. Higher scores on the scale indicate a greater need for uniqueness in a consumer context. A sample item is, "I often think of the things I buy and do in terms of how I can use them to shape a more unusual personal image." Construct reliability was 0.88 for this construct. Individual parameter estimates ranged from 0.58 to 0.81 .

Market Mavenism. Market mavenism was measured with the use of four items from Feick and Price's (1987) six-item market-maven scale. The scale measures the extent to which consumers are informed about the general marketplace and share that information with other consumers. Higher scores on the scale indicate a greater tendency toward market mavenism. A sample item is, "People ask me for information about products, places to shop, or sales." Construct reliability was 0.86 for this construct. Individual parameter estimates ranged from 0.70 to 0.88 .

Domain-Specific Opinion Leadership. Domain-specific opinion leadership was measured with the use of five items from the Flynn et al. (1996) domain-specific opinion leader/opinion seeker scale. The scale measures the extent to which an individual influences the purchasing behavior of others in a specific product domain. The scale was adapted to the product domain of fashion. A higher score on the scale indicates higher level of opinion leadership in fashion. A sample item 
is, "I often influence people's opinion about fashion." Construct reliability was 0.91 for this construct. Individual parameter estimates ranged from 0.74 to 0.89 .

\section{RESULTS}

Descriptive statistics (correlations, average variance extracted, and shared variances) appear in Table 1, along with the measurement model fit statistics. Reliabilities, assessed via coefficient alpha and the Fornell and Larcker (1981) construct reliability, are in Table 1 as well.

\section{Measurement Model}

The two-step approach advocated by Anderson and Gerbing (1988) was utilized to test the hypothesized research model. Confirmatory factor analysis (CFA) was used to further refine the measures for input into the structural-equation model (SEM). Additional items were removed from the scales on the basis of their measurement properties (loading and variance extracted) to further purify the measures. The resulting 38-item, six-factor structural measurement model was tested to evaluate the fit, convergent validity, discriminant validity, and reliability of the measures. Reference to results indicates that the resulting measurement model provides a good fit to the data. The chi-square $\left(\chi^{2}\right)$ statistic was significant, which is not surprising considering its sensitivity to sample size (Gerbing \& Anderson, 1993). The comparative fit index (CFI), the TuckerLewis index (TLI), the root-mean-square error of approximation (RMSEA), and the standardized root-mean-square residual (SRMR) were emphasized in the evaluation of the model because of their comparative insensitivity to sample size (Gerbing \& Anderson, 1993). The model exceeded

Table 1. Scale Analysis Results.

\begin{tabular}{lcclllll}
\hline Variable $^{\mathrm{a}}$ & $\mathrm{AVE}^{\mathrm{b}}$ & $\mathrm{SE}$ & $\mathrm{CO}$ & $\mathrm{SNI}$ & $\mathrm{NFU}$ & $\mathrm{MM}$ & $\mathrm{OL}$ \\
\hline $\mathrm{SE}$ & .51 & $(.89)^{\mathrm{c}}$ & $.00^{\mathrm{d} *}$ & $-.02^{* *}$ & $-.02^{* *}$ & $-.00^{* *}$ & $-.00^{* *}$ \\
$\mathrm{CO}$ & .50 & $-.04^{* *}$ & $(.85)$ & $-.02^{* *}$ & $-.02^{* *}$ & $-.02^{* *}$ & $-.01^{* *}$ \\
$\mathrm{SNI}$ & .62 & $-.14^{* *}$ & $-.15^{* *}$ & $(.93)$ & $-.01^{* *}$ & $-.02^{* *}$ & $-.06^{* *}$ \\
NFU & .52 & $-.13^{* *}$ & $-.14^{* *}$ & $-.08^{* *}$ & $(.88)$ & $-.02^{* *}$ & $-.05^{* *}$ \\
$\mathrm{MM}$ & .61 & $-.07^{* *}$ & $-.15^{* *}$ & $-.14^{* *}$ & $-.15^{* *}$ & $(.86)$ & $-.30^{* *}$ \\
$\mathrm{OL}$ & .66 & $-.06^{* *}$ & $-.09^{* *}$ & $-.24^{* *}$ & $-.23^{* *}$ & $-.55^{* *}$ & $(.91)$ \\
\hline
\end{tabular}

Measurement model fit: $\chi^{2}(650, N=590)=1,793.08, p<.01, \chi^{2} / d f=2.75, \mathrm{CFI}=.91, \mathrm{IFI}=.91, \mathrm{RMSEA}=$ .06 and SRMR $=.05$.

Note: ${ }^{\text {a }} \mathrm{SE}=$ self-esteem, $\mathrm{CO}=$ tendency to conform, $\mathrm{SNI}=$ consumer susceptibility to normative interpersonal influence, $\mathrm{NFU}=$ consumer need for uniqueness, $\mathrm{MM}=$ market mavenism, and $\mathrm{OL}=$ domain-specific opinion leadership; ${ }^{\mathrm{b}} \mathrm{AVE}=$ average variance extracted (Fornell \& Larcker, 1981); ${ }^{\mathrm{c}} \mathrm{CR}=$ construct reliabilities (Fornell \& Larcker, 1981) are on the diagonal; ${ }^{\mathrm{d}}$ shared variances are reported in the upper half of the matrix; listwise deletion resulted in $N=593 ; * p<.05 * * p<.01$. 
the generally accepted criteria of 0.90 for CFI and TLI (Garson, 2001; McDonald \& Ho, 2002). In addition, the model exceeded the criteria of RMSEA $\leq 0.08$ and SRMR $\leq 0.06$ (Bentler, 1995; McDonald \& Ho, 2002). Further, the ratio of $\chi^{2} / d f=2.76$, which falls within the criterion of less than 3.0 (Kline, 1998).

Discriminant validity was confirmed for the measurement model via the Fornell and Larcker (1981) method of verifying that the average variance extracted (AVE) exceeded the shared variance (i.e., squared correlations) between each of the latent construct pairs. Each construct demonstrated convergent validity by meeting or exceeding the Fornell and Larcker's (1981) criterion of AVE of 0.50 or greater. Internal consistency of the measures was confirmed with construct reliabilities that ranged from 0.85 to 0.93 . Overall, the measurement model was supported by the results of the CFA.

\section{Structural Model}

The hypothesized model was tested via structural-equation modeling. Figure 2 provides the fit of the model as well as graphical representation of the direction and strengths of the hypothesized paths. The structural model provided a satisfactory fit to the data; $\chi^{2}(653, N=590)=1,798.88$, $p<.01, \chi^{2} / d f=2.75, \mathrm{CFI}=0.91, \mathrm{IFI}=0.91, \mathrm{RMSEA}=0.058$, and $\mathrm{SRMR}$ $=0.056$. Moreover, all structural paths between constructs were significant, indicating that all hypotheses were supported. The overall hypothesized model was also supported.

As might be expected, $R^{2}$ values for the more abstract consumer personality constructs (consumer susceptibility to normative interpersonal influence $\left[R^{2}=.04\right]$, consumer need for uniqueness $\left[R^{2}=.04\right]$ and mar-

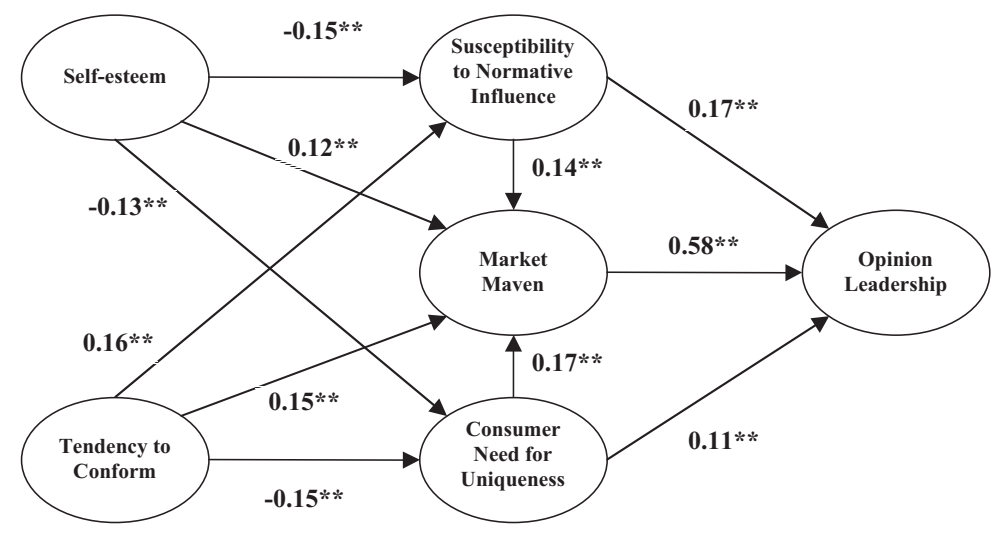

$\chi^{2}(653, N=590)=1798.88, p<.01, \chi^{2} / d f=2.75$, CFI $=91$, IFI $=.91$, RMSEA $=.058$, and SRMR $=.056$ $* p<.05 \quad * * p<.01$

Note. Consumer susceptibility to normative interpersonal influence $\left(R^{2}=.04\right)$, consumer need for uniqueness $\left(R^{2}=.04\right)$, market maven $\left(R^{2}=.08\right)$, and domain-specific opinion leadership $\left(R^{2}=.42\right)$

Figure 2. Structural model. 
ket mavenism $\left[R^{2}=.08\right]$ ) were considerably lower than the value for the domain-specific variable of opinion leadership $\left(R^{2}=.42\right)$. This is consistent with the Goldsmith et al. (1995) findings that global personality constructs typically explain far less variance than personality constructs that are specific to a product domain. Further, it supports the Goldsmith et al. (1995) call for hierarchical models that flow from abstract concepts to specific concepts. The value in these types of models is not in the explanatory power of the individual constructs. Instead, the value of the model is found in the nomological explanation of the relationships between the complex personality traits that provide the antecedents to the domain-specific variables that explain much of consumer behavior.

Three competing models were tested to provide tangible support for the specified research model. The first alternative to the hypothesized model dropped the direct paths to market mavenism from global self-esteem and tendency to conform. The theory behind the first alternative model was that the effects of self-esteem and conformity on market mavenism would be mediated by the consumer constructs of susceptibility to normative interpersonal influence and need for uniqueness. The second alternative model reversed the causal order between market mavenism and domainspecific opinion leadership and dropped direct paths to market mavenism from susceptibility to normative interpersonal influence and need for uniqueness. The theory tested by the second alternative was the idea that opinion leadership in a specific domain might lead to general market mavenism. The third alternative to the hypothesized model added paths from global self-esteem and tendency to conform to opinion leadership. The theory driving the third competing model was that antecedents of the more general market mavenism might be antecedents of domain-specific opinion leadership as well. Each alternative specification of the model significantly decreased model fit ( $p \leq .05$ ), thus supporting the hypothesized research model.

\section{DISCUSSION}

\section{Summary}

The primary contribution of the present study lies not just in the verification of individual links in the hypothesized model, but more important, in the positioning of market mavenism in a nomological network to provide better theoretical understanding of the psychological underpinnings of the construct. The purpose of this study was to provide some insight into the psychology of market mavenism in a normative context. A contribution of the resulting model is that it shows that market mavens operate within a system of social norms. Market mavens tend to conform to social norms and they are somewhat susceptible to the normative influences of those who are more likely to conform. This normative susceptibility of the market maven indicates that although they are infor- 
mation leaders in the marketplace, they do have normative boundaries that dictate how they operate as consumers. Interestingly, the model indicates that although they are susceptible to normative influence, which is associated with lower self-esteem, market mavenism is actually associated with higher self-esteem. Perhaps the low self-esteem of those consumers partially explains why they seek out advice from the market maven before making their purchase decisions. The results also indicate that despite their susceptibility to normative influence, market mavens do have a need for uniqueness expressed through their product and brand choices. This may explain why market mavens are voracious consumers of media about the marketplace. Market mavens are looking for products and brands that will distinguish themselves from the crowd, but are still acceptable to the normative beliefs of the consumers that interact with them. The relationship between market mavenism and opinion leadership has been replicated in this study in the domain of fashion, which provided additional support that market mavens are fundamentally generalized opinion leaders.

\section{Managerial Implications}

A secondary goal of this research was to give practitioners some insight into how to target market mavens with their promotion messages. The results of this study should provide some additional insight into targeting the market maven. Because market mavens are very active in spreading word-of-mouth about the general marketplace to other consumers, they are extremely valuable consumers to target. Moreover, the generalized nature of their knowledge and interactions with other consumers makes them more attractive than opinion leaders and innovators to marketers of retail stores that carry a wide variety of products. Two important observations are extricated from this study. First, market mavens are susceptible to normative influence. This indicates that market mavens are cognizant of social norms and will want to purchase products, brands, and services that do not openly violate those norms. Promotion media targeted at market mavens should imply some level of social acceptance for the product, service, or brand that is advertised. Second, market mavens have a need for uniqueness in a consumer context. Therefore, even though market mavens do not wish to violate social norms through their consumption, they want to consume products and services that distinguish them from other consumers. In other words, they desire unique products and services that are readily accepted by other consumers. Advertisements to mavens should highlight product attributes that will make the consumer of the product dissimilar from other consumers. The study highlights the complex psychological makeup of the market maven and offers many interesting questions for future research. 


\section{Limitations and Future Research}

The results of the study contribute to the understanding of the market maven, but some limitations of the research are readily apparent. First, the research is limited by the variables included in the study. A multitude of psychological variables might provide additional insight into the psychological characteristics of market maven; however, the variables in this study were intentionally constrained to normative variables that would give some insight into how the market maven operates in a social system. Second, the research is necessarily limited by the measures utilized to measure the constructs of the study. Other measures are available for the variables measured in the study (e.g., need for uniqueness), but were not included, in order to control the length of the survey. Nevertheless, the measures performed well. Third, the research is limited by the constraints of the quota sample. The purpose of the quota sample was to guarantee that a wider range of age was captured and to prevent the sample from being composed completely of student subjects. Fourth, the study is somewhat limited by the explanatory power of the personality variables included in the data collection. Personality variables are difficult to measure and are often limited in their explanatory power. However, the relationships identified in this study still provide theoretical information that can help explain the psychological attributes of the market maven.

Several avenues exist for increasing the understanding of the psychology of market mavens. The extent to which gender and age influence the normative tendencies of market mavens is not clear. Research that specifically addresses this knowledge gap would be valuable. Moreover, the authors examined the relationship between consumer need for uniqueness and market mavenism by treating consumer need for uniqueness as a unitary construct. However, it would be useful to further delineate the relationships between the dimensions of consumer need for uniqueness (creative choice counterconformity, unpopular choice counterconformity, and avoidance of similarity) and market mavenism. In addition, future research on market mavens should focus on how to specifically target these valuable consumers. Experimental research that examines the effects of targeted communications to market mavens would be especially valuable. Do market mavens respond more favorably to advertisements that portray the consumption experience or the product itself as more unique? Are market mavens attracted to advertisements for products, brands, and services that are shown to have wide acceptance by other consumers? Addressing these issues as well as other research questions pertaining to the psychological characteristics of the market maven is a worthwhile endeavor for future consumer research to undertake. This stream of research can provide additional insight into targeting this valuable consumer segment. 


\section{REFERENCES}

Anderson, J., \& Gerbing, D. (1988). Structural equation modeling in practice: A review and recommended two-step approach. Psychological Bulletin, 103, 411-423.

Asch, S. E. (1953). Effects of group pressure upon the modification and distortion of judgments. In D. Cartwright \& A. Zander (Eds.), Group dynamics. New York: Harper and Row.

Baron, R. S., Kerr, N. L., \& Miller, N. (1992). Group processes, group decision, group action. Pacific Grove, CA: Brooks/Cole.

Bearden, W. O., \& Etzel, M. J. (1982). Reference group influence on product and brand purchase decisions. Journal of Consumer Research, 9, 183-194.

Bearden, W. O., Netemeyer, R. G., \& Teel, J. E. (1989). Measurement of consumer susceptibility to interpersonal influence. Journal of Consumer Research, 15, 473-481.

Bearden, W. O., \& Rose, R. L. (1990). Attention to social comparison information: An individual difference factor affecting consumer conformity. Journal of Consumer Research, 16, 461-471.

Bentler, P. M. (1995). EQS structural equation program manual. Encino, CA: Multivariate Software.

Berkowitz, L., \& Lundy, R. M. (1957). Personality characteristics related to susceptibility to influence by peers or authority figures. Journal of Personality, 25, 306-316.

Bettman, J. R. (1979). An information processing theory of consumer choice. Reading, MA: Addison-Wesley.

Burn, S. M. (2004). Groups: Theory and practice. Belmont, CA: Thomson Wadsworth.

Burnkrant, R. E., \& Cousineau, A. (1975). Informational and normative social influence in buyer behavior. Journal of Consumer Research, 2, 206-215.

Burns, D. J., \& Warren, H. B. (1995). Need for uniqueness: Shopping mall preference and choice activity. International Journal of Retail \& Distribution Management, 23, 4-12.

Cox, D., \& Bauer, R. A. (1964). Self-confidence and personality in women. Public Opinion Quarterly, 28, 453-466.

Deutsch, M., \& Gerrard, H. B. (1955). A study of normative and informational influence upon individual judgment. Journal of Abnormal and Social Psychology, 51, 629-636.

Eastman, J. K., Goldsmith, R. E., \& Flynn, L. R. (1999). Status consumption in consumer behavior: Scale development and validation. Journal of Marketing Theory and Practice, 7, 41-52.

Elliot, M. T., \& Warfield, A. E. (1993). Do market mavens categorize brands differently? In L. McAllister \& M. L. Rothchild (Eds.), Advances in consumer research (Vol. 20, pp. 202-208).

Engelland, B. T., Hopkins, C. D., \& Larson, D. A. (2001). Market mavenship as an influencer of service quality evaluation. Journal of Marketing Theory and Practice, 9, 15-26.

Feick, L. F., \& Price L. L. (1987). The market maven: A diffuser of marketplace information. Journal of Marketing, 51, 83-97.

Feldman, D. C. (1984). The development and enforcement of group norms. Academy of Management Review, 9, 47-53. 
Fishbein, M., \& Ajzen, I. (1975). Belief, attitude, intention, and behavior. Reading, MA: Addison-Wesley.

Fisher, R. J., \& Ackerman, D. (1998). The effects of recognition and group need on volunteerism: A social norm perspective. Journal of Consumer Research, $25,262-275$.

Fisher, R. J., \& Price, L. L. (1992). An investigation into the social context of early adoption behavior. Journal of Consumer Research, 19, 477-486.

Flynn, L. R., Goldsmith, R. E., \& Eastman, J. K. (1996). Opinion leaders and opinion seekers: Two new measurement scales. Journal of the Academy of Marketing Science, 24, 137-147.

Ford, J. D., \& Ellis, E. (1980). A re-examination of group influence on member brand preference. Journal of Marketing Research, 17, 125-132.

Fornell, C., \& Larcker, D. F. (1981). Evaluating structural equation models with unobservable variables and measurement errors. Journal of Marketing Research, 18, 39-50.

Fromkin, H. L. (1972). Feelings of interpersonal indistinctiveness: An unpleasant affective state. Journal of Experimental Research in Personality, 6, 178-182.

Garson, G. D. (2001). Guide to writing empirical papers, theses and dissertations. New York: Marcel Dekker.

Gerbing, D. W., \& Anderson, J. C. (1993). Monte Carlo evaluations of goodness of fit indices for structural equation models. In K. A. Bollen \& J. S. Long (Eds.), Testing structural equation models. Newbury Park, CA: Sage.

Gilly, M. C., Graham, J. L., Wolfinbarger, M. F., \& Yale, L. J. (1998). A dyadic study of interpersonal information search. Journal of the Academy of Marketing Science, 26, 83-100.

Goldsmith, R. E., Flynn, L. R., \& Goldsmith, E. B. (2003). Innovative consumer and market mavens. Journal of Marketing Theory and Practice, 11, 54-65.

Goldsmith, R. E., Freiden, J. B., \& Eastman, J. K. (1995). The generality/specificity issue in consumer innovativeness research. Technovation, 15, 601-612.

Goldsmith, R. E., \& Hofacker, C. F. (1991). Measuring consumer innovativeness. Journal of the Academy of Marketing Science, 19, 209-221.

Guindon, M. H. (2002). Toward accountability in the use of the self-esteem construct. Journal of Counseling and Development, 80, 204-214.

Higie, R. A., Feick, L. F., \& Price, L. L. (1987). Types and amount of word-ofmouth communications about retailing. Journal of Retailing, 63, 260-278.

Im, S., Bayus B. L., \& Mason C. H. (2003). An empirical study of innate consumer innovativeness, personal characteristics, and new-product adoption behavior. Journal of the Academy of Marketing Science, 31, 61-73.

Jackson, D. N. (1976). Jackson Personality Inventory manual. Ann Arbor, MI: Research Psychologists Press.

Jahoda, M. (1959). Conformity and independence: A psychological analysis. Human Relations, 12, 99-120.

Janis, I. L. (1954). Personality correlates of persuasion. Journal of Personality, $22,504-518$.

Kline, R. B. (1998). Principles and practice of structural equation modeling. New York: Guilford Press.

Krech, D., Crutchfield, R. S., \& Ballachey, E. L. (1962). Individual in society. New York: McGraw Hill. 
Laroche, M., Pons, F., Zgolli, N., Cervellon, M. C., \& Kim, C. (2003). A model of consumer response to two retail sales promotion techniques. Journal of Business Research, 56, 513-522.

Lascu, D. N., \& Zinkhan, G. (1999). Consumer conformity: Review and applications for marketing theory and practice. Journal of Marketing Theory and Practice, 7, 1-12.

LaTour, S. A., \& Manrai, A. K. (1989). Interactive impact of informational and normative influence on donations. Journal of Marketing Research, 26, 327-335.

Leonard-Barton, D. (1985). Experts as negative opinion leaders in the diffusion of a technological innovation. Journal of Consumer Research, 11, 914-926.

Lichtenstein, D. R., \& Burton, S. (1990). An assessment of the moderating effect of market mavenism and value consciousness on price-quality perception accuracy. In M. Goldberg, G. Gorn, \& R. Pollay (Eds.), Advances in consumer research (Vol. 17, pp. 53-59), Provo, UT: The Association for Consumer Research.

McDonald, R. P., \& Ho, M. H. R. (2002). Principles and practice in reporting structural equation analyses. Psychological Methods, 7, 64-82.

McGuire, W. J. (1968). Personality and susceptibility to social influence. In E. F. Borgatta \& W. W. Lambert (Eds.), Handbook of personality theory and research (pp. 1130-1187). Chicago: Rand McNally.

McWhirter, B. T. (1997). Loneliness, learned resourcefulness, and self-esteem in college students. Journal of Counseling and Development, 6, 460-469.

Midgley, D. F., \& Dowling, G. R. (1978). Innovativeness: The concept and its measurement. Journal of Consumer Research, 4, 229-242.

Milgram, S. (1963). Behavioral study of obedience. Journal of Abnormal and Social Psychology, 67, 371-378.

Moschis, G. P. (1976). Social comparison and informal group influence. Journal of Marketing Research, 13, 237-244.

Nail, P. R., MacDonald, G., \& Levy, D. A. (2000). Proposal of a four-dimensional model of social response. Psychological Bulletin, 126, 454-470.

Nataraajan, R., \& Angur, M. G. (1997). A quest for the "industrial maven." Industrial Marketing Management, 26, 353-362.

Park, C. W., \& Lessig, P. V. (1977). Students and housewives: Differences in susceptibility to reference group influence. Journal of Consumer Research, 4, 102-110.

Price, L. L., Feick, L. F., \& Guskey, A. (1995). Everyday market helping behavior. Journal of Public Policy and Marketing, 14, 255-266.

Price, L. L., Feick, L. F., \& Guskey-Federouch, A. (1988). Couponing behaviors of the market maven: Profile of a super couponer. In M. J. Houston (Ed.), Advances in consumer research (Vol. 15, pp. 354-359).

Price, L. L., Feick, L. F., \& Higie, R. (1987). Information sensitive consumers and market information. The Journal of Consumer Affairs, 21, 328-341.

Reynolds, F. D., \& Darden, W. R. (1971). Mutually adaptive effects of interpersonal communication. Journal of Marketing Research, 8, 449-454.

Rogers, E. M. (1995). Diffusion of innovations (4th ed.) New York: The Free Press. Rosenberg, M. (1965). Society and the adolescent self-image. Princeton, NJ: Princeton University Press.

Rosenberg, M. (1979). Conceiving the self. Princeton, NJ: Princeton University Press. 
Rosenberg, M., Schooler, C., Schoenbach, C., \& Rosenberg, F. (1995). Global selfesteem and specific self-esteem: Different concepts, different outcomes. American Sociological Review, 60, 141-156.

Sen, S., Gurhan-Canli, Z., \& Morwitz, V. (2001). Withholding consumption: A social dilemma perspective on consumer boycotts. Journal of Consumer Research, 28, 399-417.

Sherif, M. (1963). The psychology of social norms. New York: Harper and Row.

Simonson, I., \& Nowlis, S. M. (2000). The role of explanations and need for uniqueness in consumer decision making: Unconventional choices based on reasons. Journal of Consumer Research, 27, 49-68.

Slama, M., Nataraajan, R., \& Williams, T. G. (1992). Market mavens and the relationship between smart buying and information provision: An exploratory study. In V. L. Crittenden (Ed.), Developments in marketing science (Vol. 15, pp. 90-93).

Slama, M. E., \& Williams, T. G. (1990). Generalization of the market maven's information provision tendency across product categories. In M. Goldberg, G. Gorn, \& R. Pollay (Eds.), Advances in consumer research (Vol. 17, pp. 48-52), Provo, UT: The Association for Consumer Research.

Snyder, C. R., \& Fromkin, H. L. (1977). Abnormality as a positive characteristic: The development of a scale measuring need for uniqueness. Journal of Abnormal Psychology, 86, 518-527.

Stafford, J. E. (1966). Effects of group influence on consumer brand preferences. Journal of Marketing Research, 3, 68-75.

Steenkamp, J. B. E. M., \& Gielens, K. (2003). Consumer and market drivers of the trial probability of consumer packaged goods. Journal of Consumer Research, 30, 368-384.

Steenkamp, J. B. E. M., Hofstede, F., \& Wedel, M. (1999). A cross-national investigation into the individual and national cultural antecedents of consumer innovativeness. Journal of Marketing, 63, 55-69.

Tian, K. T., Bearden, W. O., \& Hunter, G. L. (2001). Consumers' need for uniqueness: Scale development and validation. Journal of Consumer Research, 28, $50-66$.

Van Dyne, L., Vanderwalle, D., Kostova, T., Latham, M. E., \& Cummings, L. L. (2000). Collectivism, propensity to trust and self-esteem as predictors of organizational citizenship in a non-work setting. Journal of Organizational Behavior, 21, 3-23.

Venkatraman, M. P. (1989). Opinion leaders, adopters and communicative adopters: A role analysis. Psychology \& Marketing, 6, 51-68.

Villani, K. E. A., \& Wind, Y. (1975). On the usage of "modified" personality trait measures in consumer research. Journal of Consumer Research, 2, 223-228.

Vranica, S. (2004, March 9). U. S. ad spending rose 6.1\% in 2003. The Wall Street Journal, p. B6.

Wiedmann, K. P., Walsh, G., \& Mitchell V. W. (2001). The Mannmaven: An agent for diffusing market information. Journal of Marketing Communications, 7, 195-212.

Williams, T. G., \& Slama, M. E. (1995). Market mavens' purchase decision evaluative criteria: implications for brand and store promotion efforts. Journal of Consumer Marketing, 12, 4-21.

Willis, R. H. (1965). Conformity, independence and anticonformity. Human Relations, 18, 373-388. 
Zavestoski, S. (2002). The social-psychological bases of anticonsumption attitudes. Psychology \& Marketing, 19, 149-165.

The authors would like to thank Dr. Michael Brady, the reviewers, and the Executive Editor for their constructive contributions to this article.

Corrspondence regarding this article should be sent to: Ronald E. Goldsmith, College of Business, Florida State University, Tallahassee, FL 32306-1110 (rgoldsm@garnet.acns.fsu.edu). 